\title{
Profiling of hepatic clearance pathways of Pittsburgh compound $B$ and human liver cytochrome p450 phenotyping
}

Anne Van Vlaslaer ${ }^{1}$, Russell J Mortishire-Smith ${ }^{1}$, Claire Mackie ${ }^{1}$, Xavier Langlois ${ }^{2,3}$ and Mark E Schmidt ${ }^{4^{*}}$

\begin{abstract}
Background: ${ }^{11} \mathrm{C}$-PiB has been developed as a positron-emission tomography (PET) ligand for evaluating fibrillar $\beta$ amyloid $(A \beta)$ in the human brain. The ligand is rapidly metabolized, with approximately $10 \%$ of intact tracer remaining $30 \mathrm{~min}$ after injection. When ${ }^{11} \mathrm{C}-\mathrm{PiB}$ is used as a treatment endpoint in intervention studies for Alzheimer's disease (AD), a concern is whether the clearance of the tracer changes from one scan to the next, increasing within subject variability in the PET signal. Subjects enrolled in AD trials may start or stop medications that inhibit or induce xenobiotic metabolizing enzymes such as the cytochrome P450 (CYP) isozymes.
\end{abstract}

Findings: We conducted CYP phenotyping in recombinantly expressed systems, and in human liver microsomes, to evaluate CYP isozyme contributions to the metabolism of PiB (carrier) and profiled microsomal and hepatocyte incubations for metabolites. The metabolism of PiB appears to be polyzymic, with direct conjugation via UDPglucuronosyltransferases (UGTs) also occurring.

Conclusion: It is unlikely that CYP inhibition or induction will significantly influence the clearance of ${ }^{11} \mathrm{C}-\mathrm{PiB}$.

Keywords: Amyloid, Pittsburgh compound B, Drug metabolism, Hepatic clearance, P450 phenotyping

\section{Findings}

\section{Background}

The thioflavin $\mathrm{T}$ derivative, $N$-methyl- $\left[{ }^{11} \mathrm{C}\right] 2-(4$ 'methylaminophenyl)-6 hydroxybenzothiazole $\left({ }^{11} \mathrm{C}-\mathrm{PiB}\right)$, has been developed as a positron-emission tomography (PET) ligand for evaluating fibrillar $\beta$-amyloid $(A \beta)$ in the human brain. Retention of ${ }^{11} \mathrm{C}-\mathrm{PiB}$ in the cortex correlates with the distribution of insoluble deposits of $A \beta[1]$ and has been investigated extensively as a biomarker for Alzheimer's disease (AD) [2] and used as an endpoint in interventional trials [3,4]. ${ }^{11} \mathrm{C}-\mathrm{PiB}$ is rapidly cleared from the blood, with approximately $10 \%$ of intact tracer remaining $30 \mathrm{~min}$ after injection [5]. Test-retest studies conducted hours to weeks apart have reported interscan differences of less than 10\% [6]. These test-retest estimates may not predict the variability in measurement over longer periods of time, such as months to years.

\footnotetext{
* Correspondence: mschmid4@its.jnj.com

${ }^{4}$ Experimental Medicine, Janssen Research and Development, Division of Janssen Pharmaceutica, NV Turnhoutseweg 30, B-2340,

Beerse, Belgium

Full list of author information is available at the end of the article
}

A critical issue is the possible changes in clearance of the tracer as this could alter the input function into the brain. Metabolism of a tracer that depends primarily on one of the cytochrome P450 (CYP) isoenzymes could be vulnerable to inhibition by particular medications. Subjects enrolled in $\mathrm{AD}$ trials may start or stop a number of medications that inhibit or induce CYP enzymes such as statins, well-known potent inhibitors of the CYP3A isoenzymes, or experience conditions that could affect CYP expression [7]. The metabolism of the serotonin 5HT1A receptor PET ligand FCWAY is significantly reduced by pretreatment with disulfuram, a potent inhibitor of CYP2E1. The ratio of specific distribution volume of tracer in target rich to target poor regions increased twofold after pretreatment with disulfuram [8]. Such a change would confound measurement of change in $\mathrm{PiB}$ signal as an indicator of disease progression and potentially obscure detection of treatment effects using $\mathrm{PiB}$ as an endpoint. Current practice in acquiring PiB PET scans does not include any blood sampling, so changes in tracer clearance from one scan to the next would not be detected. We wished to determine the metabolic 
pathway for $\mathrm{PiB}$ to explore whether peripheral clearance of ${ }^{11} \mathrm{C}-\mathrm{PiB}$ could be susceptible to CYP inhibition or induction - specifically, whether the metabolism of $\mathrm{PiB}$ via the most abundant CYPs is mono- or polyzymic, and whether direct conjugation of $\mathrm{PiB}$ is a significant clearance pathway. While these in vitro systems are necessarily reductionist in comparison with the in vivo systems, they are generally agreed to provide valuable insight into likely in vivo outcomes.

\section{Materials and methods}

Cryopreserved human (male and female), male Beagle dog, male Sprague-Dawley rat, and male Swiss mouse hepatocytes were purchased from In Vitro Technologies (In Vitro Technologies, Baltimore, MD, USA). Sulfaphenazole and quinidine were purchased from Sigma (St. Louis, MO, USA). Alpha-naphthoflavone was purchased from Merck KGaA (Darmstadt, Germany). Benzylphenobarbital and ketoconazole were synthesized in-house. $\mathrm{PiB}$ was purchased from ABX GmbH (Radeberg, Germany). Diagnostic P450 inhibitors and test compounds were supplied as dry powder and dissolved in $100 \%$ dimethylsulfoxide (DMSO). All other materials were of analytical or higher grade and used without further purification. Cytochrome P450 isoforms 1A2, 2C9, 2C19, 2D6, and 3A4 were obtained as singly expressed enzymes (Baculovirus transfected insect cell system, rhCYPs) from BD Gentest (Woburn, MA, USA). Human liver microsomes (HLM) were obtained from BD Gentest (Woburn, MA, USA) as a pool from 50 donors, lot 01220.

\section{Incubations with recombinantly expressed cytochrome P450s}

The assay mixtures (final incubation volume of $125 \mu \mathrm{L}$ ) in $0.255 \mathrm{M}$ phosphate buffer with $0.575 \%(w / v) \mathrm{KCl}(\mathrm{pH} 7.4)$ contained $\mathrm{PiB}(1.0 \mu \mathrm{M}), 2.0 \mathrm{mM}$ nicotinamide-adenine dinucleotide phosphate (reduced form) (NADPH), and a recombinantly expressed cytochrome $\mathrm{P} 450$ enzyme preparation at $100 \mathrm{pmol} / \mathrm{mL}$. After a $10 \mathrm{~min}$ preincubation at $37^{\circ} \mathrm{C}$, the reaction was initiated by addition of $2.0 \mathrm{mM}$ $\mathrm{NADPH}$ and incubated for 15 and $60 \mathrm{~min}$. The reactions were terminated by the addition of two volumes of

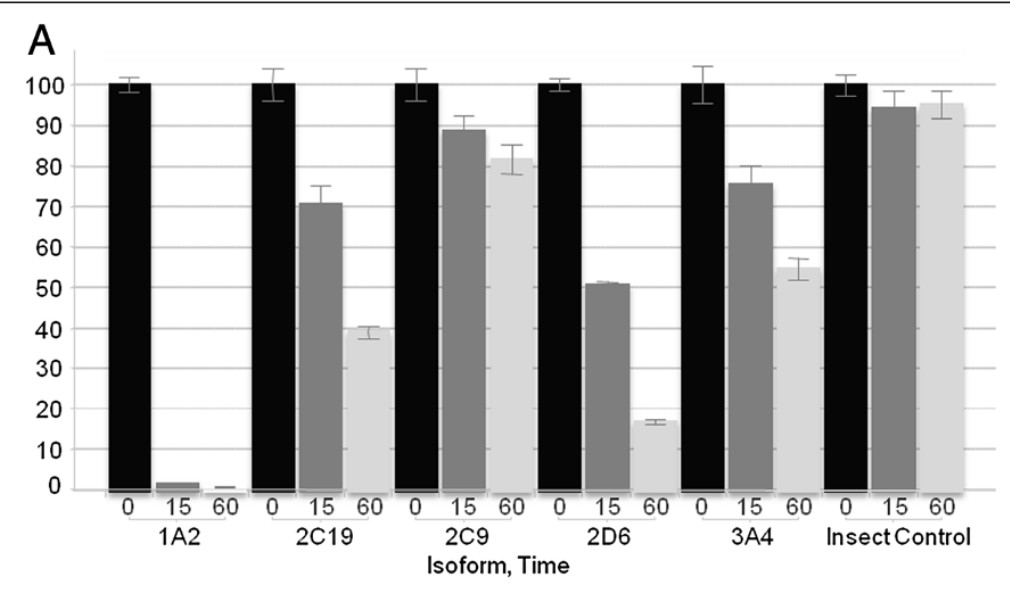

B

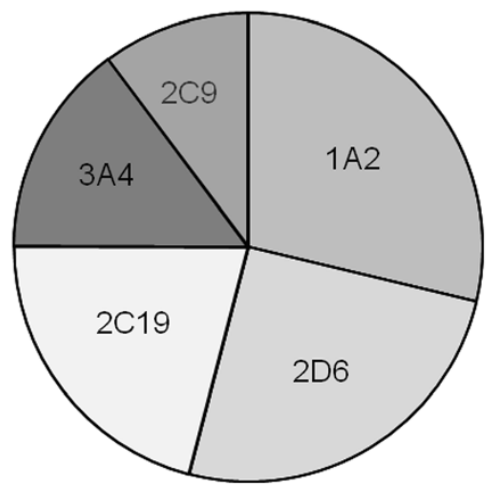

C

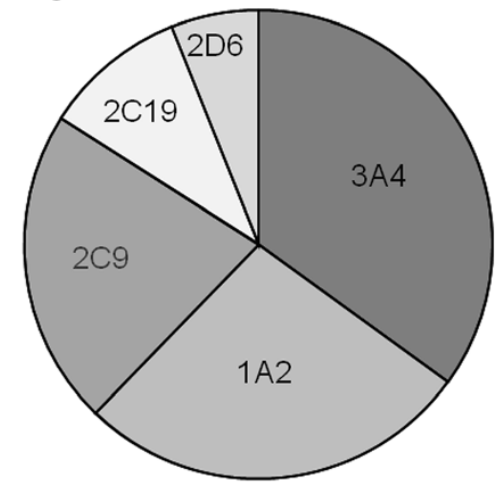

Figure 1 Percentage of PiB remaining after incubation in HLM and relative contributions to turnover. (A) \% PiB remaining after 0 (black), 15 (dark gray) and 60 min (light gray) incubations at $1 \mu \mathrm{M}$ substrate concentration with rhCYPs 1A2, 2C9, 2C19, 2D6, and 3A4. (B) Relative contributions to turnover of PiB based on unscaled rhCYP data. (C) Relative contributions to turnover of PiB after scaling for the relative abundances of CYPs in human liver, according to Rodrigues [10]. 


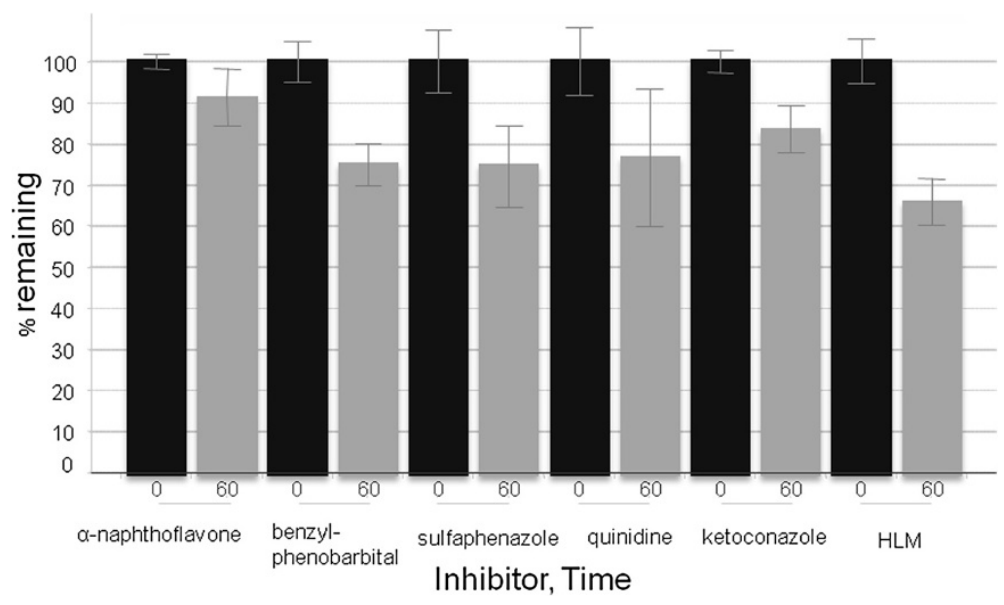

Figure 2 Percentage of PiB remaining after 60 min incubations in HLM. Percentage of PiB remaining after 0 min (black) and 60 min (dark gray) incubations in HLM at $1 \mu \mathrm{M}$ substrate concentration with no inhibition (two rightmost bars), or in the presence of CYP-specific chemical inhibitors.

DMSO. Samples were subsequently centrifuged at 4,000 rpm for $10 \mathrm{~min}$. From the resulting supernatant, $10 \mu \mathrm{L}$ was analysed by liquid chromatography/tandem mass spectrometry (LC-MS/MS). Control experiments were performed by substituting the active enzyme preparation by insect cell preparations containing no rhCYP.

\section{Human liver microsomal metabolism in the absence and presence of cytochrome P450 diagnostic inhibitors}

Assay mixtures (final incubation volume of $125 \mu \mathrm{L}$ ) in $0.255 \mathrm{M}$ phosphate buffer with $0.575 \%(w / v) \mathrm{KCl}(\mathrm{pH} 7.4)$ contained $\mathrm{PiB}(1.0 \mu \mathrm{M})$, an NADPH regenerating system (consisting of $1.65 \mathrm{mM}$ glucose-6-phosphate, $0.125 \mathrm{U}$ glucose-6-phosphate dehydrogenase, $0.1 \mathrm{mM}$ NADP, and $5.0 \mathrm{mM}$ magnesium chloride), $1.0 \mathrm{mg} / \mathrm{mL}$ of pooled human liver microsomes, and alpha-naphthoflavone (3 $\mu \mathrm{M})$, sulfaphenazole $(10 \mu \mathrm{M})$, benzylphenobarbital $(1 \mu \mathrm{M})$, quinidine $(3 \mu \mathrm{M})$, or ketoconazole $(1 \mu \mathrm{M})$, and inhibitors of cytochromes P450 1A2, 2C9, 2C19, 2D6, and $3 \mathrm{~A} 4$, respectively. After a $10 \mathrm{~min}$ preincubation at $37^{\circ} \mathrm{C}$, the reaction was initiated by addition of $0.15 \mathrm{mM}$ NADP and further incubated for either 15 or $60 \mathrm{~min}$. The reactions were terminated by the addition of two volumes DMSO. Samples were subsequently centrifuged at 4,000 $\mathrm{rpm}$ for $10 \mathrm{~min}$. From the resulting supernatant, $10 \mu \mathrm{L}$ was analyzed by LC-MS/MS.

\section{Hepatocyte incubations}

$\mathrm{PiB}$ was incubated in 24-well plates at a final concentration of $1.0 \mu \mathrm{M}$ for 0,15 , and $60 \mathrm{~min}$, with hepatocyte cell cultures ( 1 million viable cells $/ \mathrm{mL})$, after which the incubations were quenched with two volumes of acetonitrile.

\section{LC-MS/MS detection}

Quantification was performed on a TSQ-Vantage instrument (Thermofisher Scientific, Bremen, Germany), fitted<smiles>CNc1ccc(-c2nc3ccc(OC4OC(C(=O)O)C(O)C(O)C4O)c(CCNc4ccc(O)cc4)c3s2)cc1</smiles>

Figure 3 Metabolites identified in incubations with human liver microsomes and hepatocytes. 
with an electrospray ionization source. The S-lens voltage was set to $78 \mathrm{~V}$, and the intensity of two transitions $(257>242$ at a collision energy $(\mathrm{CE})=27 \mathrm{~V} ; 257>215$, $\mathrm{CE}=36 \mathrm{~V}$ ) were measured during the experiment. Elution was performed on a Waters XBridge C18 column $(3 \times 2.1 \mathrm{~mm}, 2.5 \mu \mathrm{m}$; Waters, Boston MA, USA). Solvents A $(0.1 \%$ formic acid in water) and B $(0.1 \%$ formic acid in acetonitrile) were used at a flow rate of $500 \mu \mathrm{L} / \mathrm{min}$. The gradient employed was solvent A $95 \%$ as the start condition followed by a linear ramp of organic phase concentration from 5\% B to 95\% B over $1.3 \mathrm{~min}$. The final ratio was held for a further $0.6 \mathrm{~min}$ and then reduced again to $5 \% \mathrm{~B}$ over 0.05 min. Data was processed using QuickQuan (Thermofisher Scientific, Bremen, Germany).

Qualitative high resolution LC/MS data was acquired on a Waters Premier hybrid quadrupole time-of-flight (QToF) mass spectrometer (Waters, Boston MA, USA) equipped with a liquid chromatography system, using a 10 min gradient method and an Acquity UPLC BEH C18 $(2.1 \times 100 \mathrm{~mm}, 1.7 \mu \mathrm{m})$ column (Waters, Boston MA). The QToF Premier operated with a cone voltage of $30 \mathrm{eV}$ and collision energy of $30 \mathrm{eV}$. The gradient employed was $95 \%$ solvent A $(25 \mathrm{mM}$ ammonium acetate, $\mathrm{pH}=9$ ) as the start condition followed by a linear ramp of organic phase concentration from 5\% B (25 mM ammonium acetate/MeOH/acetonitrile $10 / 10 / 80$ ) to
95\% B over $6.5 \mathrm{~min}$. The final ratio was held for $2 \mathrm{~min}$ and then reduced again to $5 \% \mathrm{~B}$ over $1 \mathrm{~min}$. Interpretation of data was performed with Metabolynx software (Waters, Boston, MA, USA) [9].

\section{Results}

Based on the observed turnovers, $\mathrm{PiB}$ is a substrate for all five of the major human CYPs, with rhCYP1A2 dominating. Each incubation only contains a single CYP at an effective abundance of $100 \%$. Scaling for the approximate relative abundances of the major five CYP isoforms in human liver [10] indicates that $\mathrm{PiB}$ is likely to be primarily metabolized by CYPs 3A4, 1A2, and 2C9, with only minor contributions from 2C19 and 2D6 (Figure 1A,B).

The turnover of $\mathrm{PiB}$ in human liver microsomes was approximately $35 \%$ after $60 \mathrm{~min}$. A significant reduction in turnover was observed with inhibitors of CYPs $1 \mathrm{~A} 2$ and $3 \mathrm{~A} 4$, and a reduction in turnover is also apparent for CYPs 2C19, 2C9, and 2D6 (Figure 2).

The HLM incubations from the phenotyping experiments and the separate incubations performed with human, rat, dog, and mouse hepatocytes were profiled for $\mathrm{PiB}$ metabolites. The only drug-related species detected in HLM was the desmethyl metabolite. Additionally present in human hepatocyte incubations were two glucuronide conjugates, assumed to be formed by
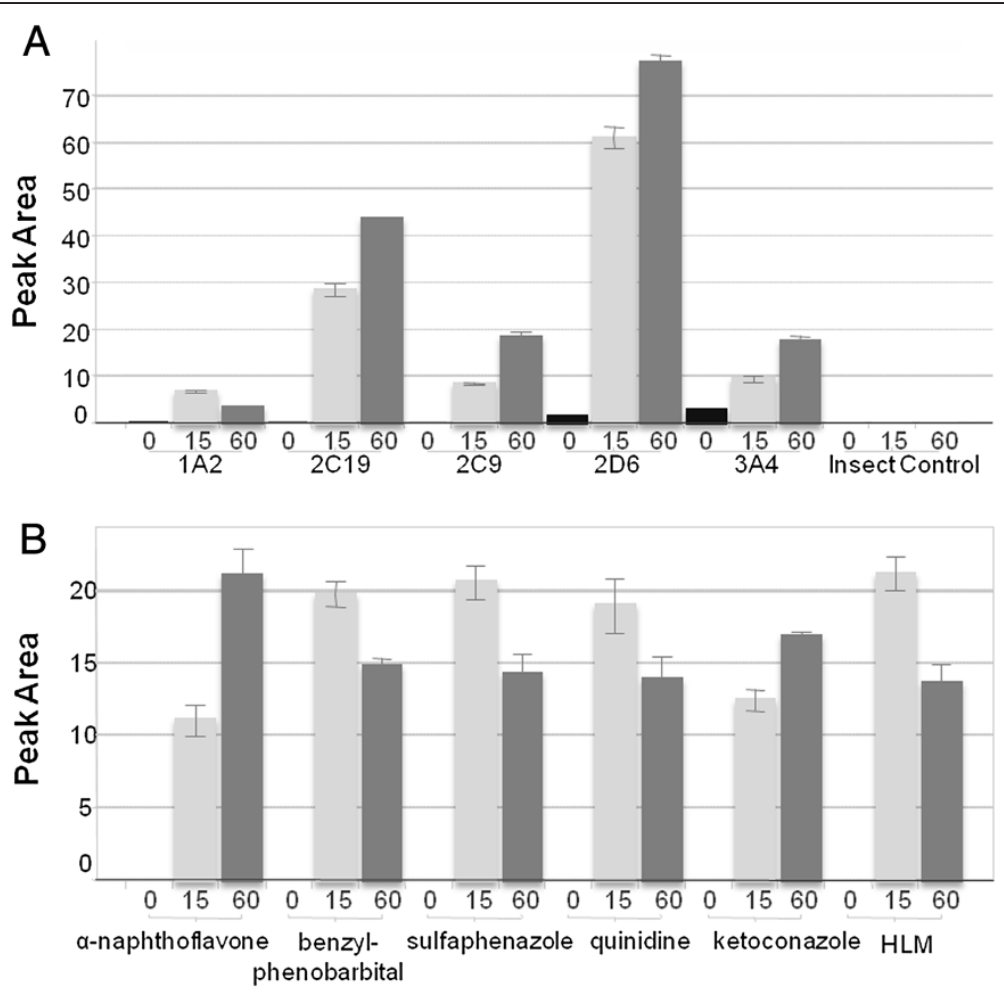

Figure 4 Peak areas observed for the desmethyl metabolite. (A) RhCYP incubations. (B) Incubations with HLM in the presence or absence of chemical inhibitors. 
direct glucuronidation of the phenolic hydroxyl group and of the secondary amine. A combination demethylation/glucuronidation metabolite was also detected, but it was not possible to assign the glucuronidation site for this metabolite (Figure 3).

In rhCYP incubations, the desmethyl metabolite was the only drug-related species observed. Despite high turnover with 1A2 (and 3A4), only low levels of the desmethyl metabolite were present. In the HLM incubations with inhibitors of $1 \mathrm{~A} 2$ and $3 \mathrm{~A} 4$, concentrations of the desmethyl metabolite increased over time, while with $2 \mathrm{C} 19,2 \mathrm{C} 9$, and 2D6, concentrations were reduced at 60 min compared with $15 \mathrm{~min}$ (Figure 4). These data are together consistent with a two-step pathway in which all isoforms are able to demethylate, but $1 \mathrm{~A} 2$ and $3 \mathrm{~A} 4$ can then metabolize the desmethyl metabolite to a secondary product not detectable within the limits of detection of the qualitative LC/MS method used.

\section{Discussion}

The results of experiments using in vitro human systems indicate that $\mathrm{PiB}$ is metabolized via both oxidative and conjugative mechanisms. The dominant routes of metabolism are $\mathrm{N}$-demethylation and glucuronidation. The metabolism of $\mathrm{PiB}$ appears to be polyzymic, with at least two of the major human CYPs (1A2 and 3A4), contributing to metabolism, together with UDP-glucuronosyltransferase (UGT) involvement.

These results assume that the principal pathways observed in these in vitro human metabolizing systems translate to in vivo. In vivo drug metabolism is typically found to be more, not less complex than that observed in vitro and one metabolite known to be formed in man, a sulfate conjugate [11], was not observed in these experiments. Moreover, the absolute contributions of oxidation and conjugation to clearance cannot be measured without authentic standards. A fuller understanding of the enzyme kinetics involved in biotransformation of $\mathrm{PiB}$ would afford improved predictions of its in vivo pharmacokinetics and susceptibility to drug-drug interactions. Even so, the multiple pathways determined here to be involved in the metabolic clearance of $\mathrm{PiB}$ reduce the likelihood that drug-drug interactions are a source of variability in quantitative measurement of ${ }^{11} \mathrm{C}$-PiB PET.

\section{Competing interests}

All authors are full time employees of Janssen Pharmaceutica, N.V. None of the authors have financial interests in GE Healthcare, the commercial license holder of the ${ }^{11} \mathrm{C}-\mathrm{PiB}$ technology; nor with the University of Pittsburgh, the licensor of the technology. Janssen Pharmaceutica, N.V. is engaged in the discovery and development of new treatments for Alzheimer's disease. Availability of reliable methods of longitudinal measurement of brain fibrillar amyloid using PET may be of critical importance for interventional studies of Alzheimer's disease.

\section{Authors' contributions}

AW conducted all in vitro assays for CYP phenotyping, microsomal and hepatocyte incubations, and drafted the manuscript. RMS selected the in vitro assays, reviewed and approved all results, and provided the interpretation of metabolic pathways. CM drafted the research plan. XL contributed to experimental design and conducted supportive studies. MES conceived the project and assisted in the interpretation of results. All authors contributed to the writing and review of the reports and have read and approved the manuscript.

\section{Acknowledgments}

The authors would like to acknowledge Chet Mathis (University of Pittsburgh) for his helpful comments on the metabolism of ${ }^{11} \mathrm{C}-\mathrm{PiB}$, and Dawn Mathews (ADMdx, Chicago, IL) for her observations on the dynamic data in longitudinal ${ }^{11} \mathrm{C}$-PiB PET studies that led to investigating influences on tracer clearance.

\section{Author details}

${ }^{1}$ C.R.E.A.Te, Janssen Pharmaceutical Companies of Johnson \& Johnson, Turnhoutseweg 30, B-2340, Beerse, Belgium. ²Project Management Office, Janssen Pharmaceutical Companies of Johnson \& Johnson, Turnhoutseweg 30, B-2340, Beerse, Belgium. ${ }^{3}$ Neuroscience TA, Janssen Pharmaceutical Companies of Johnson \& Johnson, Turnhoutseweg 30, B-2340, Beerse, Belgium. "Experimental Medicine, Janssen Research and Development, Division of Janssen Pharmaceutica, NV Turnhoutseweg 30, B-2340, Beerse, Belgium.

Received: 25 November 2012 Accepted: 30 January 2013 Published: 14 February 2013

\section{References}

1. Ikonomovic MD, Klunk WE, Abrahamson EE, Mathis CA, Price JC, Tsopelas ND, Lopresti BJ, Ziolko S, Bi W, Paljug WR, Debnath ML, Hope CE, Isanski BA, Hamilton RL, DeKosky ST: Post-mortem correlates of in vivo PiB-PET amyloid imaging in a typical case of Alzheimer's disease. Brain 2008, 131(Pt 6):1630-1645.

2. Jack CR Jr, Lowe VJ, Weigand SD, Wiste HJ, Senjem ML, Knopman DS, Shiung MM, Gunter JL, Boeve BF, Kemp BJ, Weiner M, Petersen RC: Alzheimer's Disease Neuroimaging Initiative: Serial PIB and MRI in normal, mild cognitive impairment and Alzheimer's disease: implications for sequence of pathological events in Alzheimer's disease. Brain 2009, 132(Pt 5):1355-1365.

3. Rinne JO, Brooks DJ, Rossor MN, Fox NC, Bullock R, Klunk WE, Mathis CA, Blennow K, Barakos J, Okello AA, Rodriguez Martinezde Llano S, Liu E, Koller M, Gregg KM, Schenk D, Black R, Grundman M: 11C-PiB PET assessment of change in fibrillar amyloid-beta load in patients with Alzheimer's disease treated with bapineuzumab: a phase 2, double-blind, placebo-controlled, ascending-dose study. Lancet Neurol 2010, 9(4):363-372.

4. Ostrowitzki S, Deptula D, Thurfjell L, Barkhof F, Bohrmann B, Brooks DJ, Klunk WE, Ashford E, Yoo K, Xu ZX, Loetscher H, Santarelli L: Mechanism of amyloid removal in patients with Alzheimer disease treated with gantenerumab. Arch Neurol 2011, 69:198-207.

5. Price JC, Klunk WE, Lopresti BJ, Lu X, Hoge JA, Ziolko SK, Holt DP, Meltzer CC, DeKosky ST, Mathis CA: Kinetic modeling of amyloid binding in humans using PET imaging and Pittsburgh compound-B. J Cereb Blood Flow Metab 2005, 25(11):1528-1547.

6. Tolboom N, Yaqub M, Boellaard R, Luurtsema G, Windhorst AD, Scheltens $P$, Lammertsma AA, van Berckel BNM: Test-retest variability of quantitative [11C]PIB studies in Alzheimer's disease. Eur J Nucl Med Mol Imaging 2009, 36(10):1629-1638.

7. Aitken $A E$, Morgan ET: Gene-specific effects of inflammatory cytokines on cytochrome P450 2C, 2 B6 and 3A4 mRNA levels in human hepatocytes. Drug Metab Dispos 2007, 35(9):1687-1693.

8. Ryu YH, Liow JS, Zoghbi S, Fujita M, Collins J, Tipre D, Sangare J, Hong J, Pike WW, Innis RB: Disulfiram inhibits defluorination of 18 F-FCWAY, reduces bone radioactivity, and enhances visualization of radioligand binding to serotonin 5-HT1A receptors in human brain. J NuCl Med 2007, 48(7):1154-1161.

9. Mortishire-Smith RJ, O'Connor D, Castro-Perez JM, Kirby J: Accelerated throughput metabolic route screening in early drug discovery using high-resolution liquid chromatography/quadrupole time-of-flight mass 
spectrometry and automated data analysis. Rapid Commun Mass Spectrom 2005, 19(18):2659-2670.

10. Rodrigues AD: Integrated cytochrome $\mathbf{P} 450$ reaction phenotyping: attempting to bridge the gap between CDNA-expressed cytochromes P450 and native human liver microsomes. Biochem Pharmacol 1999, 57(5):465-480.

11. Mathis CA, Holt DP, Wang Y, Huang GF, Debnath ML, Shao L, Klunk WE: Species-dependent metabolism of the amyloid imaging agent [C-11]PIB. J Nucl Med 2004, 45:114P.

doi:10.1186/2191-219X-3-10

Cite this article as: Van Vlaslaer et al:: Profiling of hepatic clearance

pathways of Pittsburgh compound B and human liver cytochrome p450 phenotyping. EJNMMI Research 2013 3:10.

\section{Submit your manuscript to a SpringerOpen ${ }^{\odot}$ journal and benefit from:}

- Convenient online submission

- Rigorous peer review

- Immediate publication on acceptance

- Open access: articles freely available online

- High visibility within the field

- Retaining the copyright to your article 